\title{
Update on GOSAT TANSO-FTS performance, operations, and data products after more than 6 years in space
}

\author{
Akihiko Kuze $^{1}$, Hiroshi Suto ${ }^{1}$, Kei Shiomi ${ }^{1}$, Shuji Kawakami ${ }^{1}$, Makoto Tanaka ${ }^{1}$, Yoko Ueda ${ }^{1}$, Akira Deguchi ${ }^{1}$, \\ Jun Yoshida $^{2}$, Yoshifumi Yamamoto ${ }^{3}$, Fumie Kataoka ${ }^{4}$, Thomas E. Taylor ${ }^{5}$, and Henry L. Buijs ${ }^{6}$ \\ ${ }^{1}$ Japan Aerospace Exploration Agency, Tsukuba, Ibaraki, Japan \\ ${ }^{2}$ NEC Cooperation, Fuchu, Tokyo, Japan \\ ${ }^{3}$ NEC Informatec Systems, Ltd., Kawasaki, Kanagawa, Japan \\ ${ }^{4}$ Remote Sensing Technology Center of Japan, Tsukuba, Ibaraki, Japan \\ ${ }^{5}$ Cooperative Institute for Research in the Atmosphere, Colorado State University, \\ Fort Collins, CO, USA \\ ${ }^{6} \mathrm{ABB}$, Inc., Québec City, Québec, Canada \\ Correspondence to: Akihiko Kuze (kuze.akihiko@jaxa.jp)
}

Received: 7 November 2015 - Published in Atmos. Meas. Tech. Discuss.: 18 January 2016

Revised: 10 May 2016 - Accepted: 12 May 2016 - Published: 2 June 2016

\begin{abstract}
A data set containing more than 6 years (February 2009 to present) of radiance spectra for carbon dioxide $\left(\mathrm{CO}_{2}\right)$ and methane $\left(\mathrm{CH}_{4}\right)$ observations has been acquired by the Greenhouse gases Observing SATellite (GOSAT, available at http://data.gosat.nies.go.jp/ GosatUserInterfaceGateway/guig/GuigPage/open.do), nicknamed "Ibuki", Thermal And Near infrared Sensor for carbon Observation Fourier Transform Spectrometer (TANSOFTS). This paper provides updates on the performance of the satellite and TANSO-FTS sensor and describes important changes to the data product, which has recently been made available to users. With these changes the typical accuracy of retrieved column-averaged dry air mole fractions of $\mathrm{CO}_{2}$ and $\mathrm{CH}_{4}\left(\mathrm{X}_{\mathrm{CO}_{2}}\right.$ and $\mathrm{X}_{\mathrm{CH}_{4}}$, respectively) are $2 \mathrm{ppm}$ or $0.5 \%$ and $13 \mathrm{ppb}$ or $0.7 \%$, respectively. Three major anomalies of the satellite system affecting TANSO-FTS are reported: a failure of one of the two solar paddles in May 2014, a switch to the secondary pointing system in January 2015, and most recently a cryocooler shutdown and restart in August 2015. The Level 1A (L1A) (raw interferogram) and the Level 1B (L1B) (radiance spectra) of version V201 described here have longterm uniform quality and provide consistent retrieval accuracy even after the satellite system anomalies. In addition, we discuss the unique observation abilities of GOSAT made possible by an agile pointing mechanism, which allows for optimization of global sampling patterns.
\end{abstract}

\section{Introduction}

\subsection{Overview}

The Greenhouse gases Observing SATellite (GOSAT), launched on 23 January 2009, carries two independent sensors, the Thermal And Near infrared Sensor for carbon Observation Fourier Transform Spectrometer (TANSO-FTS) and the Cloud and Aerosol Imager (TANSO-CAI) (Kuze et al., 2009). The objective of the mission is to provide long-term monitoring of column-averaged dry air mole fractions of carbon dioxide $\left(\mathrm{CO}_{2}\right)$ and methane $\left(\mathrm{CH}_{4}\right)\left(\mathrm{X}_{\mathrm{CO}_{2}}\right.$ and $\mathrm{X}_{\mathrm{CH}_{4}}$, respectively) over much of the globe. After the Scanning Imaging Absorption Spectrometer for Atmospheric CHartographY (SCIAMACHY) stopped its operation in April 2012 and prior to the launch of the Orbiting Carbon Observatory-2 (OCO-2) in July 2014, GOSAT was the only instrument that could provide $\mathrm{CO}_{2}$ and $\mathrm{CH}_{4}$ column amounts, which are sensitive to the surface from space (Crisp et al., 2012; http://disc.sci.gsfc.nasa.gov/acdisc/ documentation/ACOS.html; Yoshida et al., 2013).

By providing long-term high-resolution spectral data, TANSO-FTS is a pathfinder for subsequent missions such as OCO-2, which was launched in 2014 (Crisp et al., 2004) and TROPOspheric Monitoring Instrument (TROPOMI) and TanSat, which are scheduled for launch in 2016 (Veefkind et al., 2012; Liu et al., 2013). GOSAT and these missions 


\begin{tabular}{|c|c|c|c|c|c|c|c|}
\hline & 2009 & 2010 & 2011 & 2012 & 2013 & 2014 & 2015 - \\
\hline Milestone & Launch & & & & & $\begin{array}{l}*{ }^{*}{ }^{*} \\
\text { Solar paddle accident } \\
\text { Unstable pointing }\end{array}$ & \begin{tabular}{|l|}
$*$ \\
Switching pointing mechanism \\
Cryocooler suspend
\end{tabular} \\
\hline $\begin{array}{l}\text { FTS nominal } \\
\text { pointing pattern }\end{array}$ & \multicolumn{2}{|l|}{$5 \mathrm{p}-\mathrm{CT}$} & \multicolumn{2}{|c|}{ 3p-CT } & & $1,3 \mathrm{p}-\mathrm{CT}$ & $3 p-C T$ \\
\hline FTS pointing & \multicolumn{6}{|c|}{ Primary } & Secondary \\
\hline $\begin{array}{l}\text { FTS } \\
\text { interferogram }\end{array}$ & \multicolumn{5}{|c|}{ No bias } & \multicolumn{2}{|c|}{800 fringes bias } \\
\hline \multirow[t]{2}{*}{ FTS operation } & \multicolumn{6}{|c|}{ SWIR (S) and TIR (T) } & $s$ \\
\hline & & & & & & & \\
\hline
\end{tabular}

Figure 1. Long-term operation status. Note: there is no change in the operation of TANSO-CAI and CAM.

have different observation strategies. TANSO-FTS has wide spectral coverage from SWIR to TIR and an agile pointing system at the expense of spatial context, while OCO-2 and TROPOMI measure greenhouse gases (GHGs) with higher spatial resolution using imaging grating spectrometers.

Since launch, the Level 1A (L1A) (raw interferogram) and the Level 1B (L1B) (radiance spectra) have been updated 10 times: versions of V006, V007, V050, V080, V100, V110, V130, V150, V161, and V201 (Kuze et al., 2012). Kuze et al. (2014) provided the radiance degradation factors (RDFs) for long-term radiometric correction after launch. Several analyses and laboratory experiments have improved the accuracy of the solar lines and molecular line parameters (Toon et al., 2015; Long et al., 2012; Thompson et al., 2012). The accuracy and degree of convergence of the retrieval algorithms has been improved by fitting the most persistent spectral residuals with the empirical orthogonal functions ( $\mathrm{O}^{\prime}$ Dell et al., 2013). These efforts have reduced radiative transfer calculation errors.

This paper describes the long-term performance and operation of GOSAT TANSO-FTS. Section 2 summarizes improvements of the radiometric and geometric calibrations. Section 3 describes changes to L1B processing and the user product for the new L1B version V201 release. Finally, Sect. 4 discusses changes to the TANSO-FTS observation pattern with the aim of optimizing the global coverage of the measurement set and providing targeted measurements over emission sources such as megacities, oil fields, and volcanos. Section 5 provides a summary of the changes and discusses the future role of GOSAT in GHG observations from space. It also provides an inter-comparison with the newer OCO2 satellite. The TANSO-CAI radiometric calibration is also described in Sect. 2.

\subsection{The use of GOSAT data}

Multiple teams from more than 10 countries have been working on independent retrievals of $\mathrm{X}_{\mathrm{CO}_{2}}$ and $\mathrm{X}_{\mathrm{CH}_{4}}$ with errors of less than $2 \mathrm{ppm}(0.5 \%)$ and $13 \mathrm{ppb}(0.7 \%)$, respectively, over much of the globe. These data sets have not only reduced uncertainty in global $\mathrm{CO}_{2}$ flux estimates but also been used to monitor regional emissions such as $\mathrm{CO}_{2}$ from megac- ities and $\mathrm{CH}_{4}$ from oil fields, coal power plants, landfills, and livestock (Kort et al., 2011; Turner et al., 2015). Furthermore, the first high-resolution spectra of plant fluorescence from space have presented patterns of gross primary productivity and opened a new viewpoint to the carbon cycle (Frankenberg et al., 2011). From long-term GOSAT data, regionalscale GHG variation has been analyzed and new findings such as regional growth rates, European $\mathrm{CO}_{2}$ uptake, $\mathrm{CH}_{4}$ mapping over Monsoon Asia, and enhancement of 2015 Indonesian biomass burning are presented recently (Lindqvist et al., 2015; Feng et al., 2016; Massart et al., 2016; Liu et al., 2016; Parker et al., 2016). The literature highlights the need for consistent spectral quality and seamless data.

\section{Long-term operation and calibrations}

The long-term operation of over 6 years is summarized in Fig. 1 and calibration activity is described in this section.

\subsection{Operation before three major anomalies}

Except for single-event anomalies caused by cosmic radiation on the star tracker, the mission data processor, and the GPS receiver, all the components of the satellite bus and two instruments had been working normally until 24 May 2014. The degree of degradation of less than $10 \%$ of the four batteries indicated that power generation degradation was much less than $1 \%$ and the satellite bus batteries did not show significant degradation. Enough fuel remained for 14 more years of operation as of February 2014, at which point the 5 -year design lifetime had passed. Every 2.5 years, an outof-plane orbit control for the adjustment of the inclination of the orbit phase is performed to keep the local overpass time between 12:46 and 12:51. In July and August 2011 and December 2013, GOSAT suspended observations several times; during these control periods, observations were collected using the nominal three-point cross-track (CT) scan mode without glint and target observations (Kuze et al., 2012).

Kuze et al. (2012) listed the TANSO-FTS items that gradually change with time or occur periodically: (1) the zero path difference (ZPD) shifts in the FTS, (2) the FTS laser signal detection level, and (3) the pointing offset. Up-and- 
down zero crossings of laser fringes (half laser fringe) are utilized for sampling triggers, which result in 76336 sampling points per interferogram. A fringe counter counts fringes up in the forward scan direction and down in the reverse scan direction. The ideal ZPD position is the center of the sampling points, which is maintained under nominal operation. The occurrence of occasional count errors at the scan turnaround causes shift in the ZPD position. Excessive ZPD shifts could lead to spectral resolution changes unless the interferogram is processed with an asymmetric weighting function as described later. Precisely the same spectral resolution has been maintained for all retrieved spectra either by repositioning ZPD or by applying an asymmetric weighting function when the shift is too large. The root cause of the ZPD shift is a combination of degraded laser detection levels, the turnaround time duration of the FTS mechanism, and microvibrations of the Earth sensor of the satellite attitude control at $244 \mathrm{~Hz}$. The ZPD shifts had been carefully corrected by shifting the FTS scan position before the bias reaches 50 half laser fringes until May 2014. After periodic corrections, the absolute ZPD shift value has been kept lower than 100 half laser fringe and hence the precise spectral resolution has been maintained for these conditions in all spectral retrievals as shown in Fig. 2. About $70 \%$ of the data between July 2009 and July 2010 and almost $100 \%$ of the data between August 2010 and May 2014 are well controlled and not processed with an asymmetric weighting function. The detected laser signal amplitude of dephase and fringe channels indicate that there will be enough margin for future operation, as shown in Fig. 3. The phase-delayed dephase signal is used to control the FTS scan direction and the fringe provides the sampling trigger. While the CT motion controlled by the micro stepper motor of the TANSO-FTS pointing mechanism assembly is stable, complicated along-track (AT) motion has caused fluctuations (Fig. 4). To avoid pointing fluctuations caused by inadequate power to actuate the hardened cable in the primary pointing system, the AT pointing angle range was limited between $-16.0^{\circ}$ (backward) and $19.4^{\circ}$ (forward) instead of the originally designed $\pm 20^{\circ}$.

There is no functional and performance change on orbit in TANSO-CAI since launch except for the gradual radiometric degradation. The dark current levels of the bands 1,2 , and 3 Charge-Coupled Device (CCD) detectors have gradually increased. As of October 2015, 26 out of 512 pixels of the band 4 InGaAs detector with complementary metal oxide semiconductor (CMOS) readouts show abnormal large darklevel values. The integration time for the all four bands has not been changed. TANSO-CAI has been operated continuously except for short period after the solar paddle anomaly in May 2014.

\subsection{Solar-paddle-rotation anomaly}

On 24 May 2014, rotation of one of the two solar paddles stopped, probably because of a single event in the control

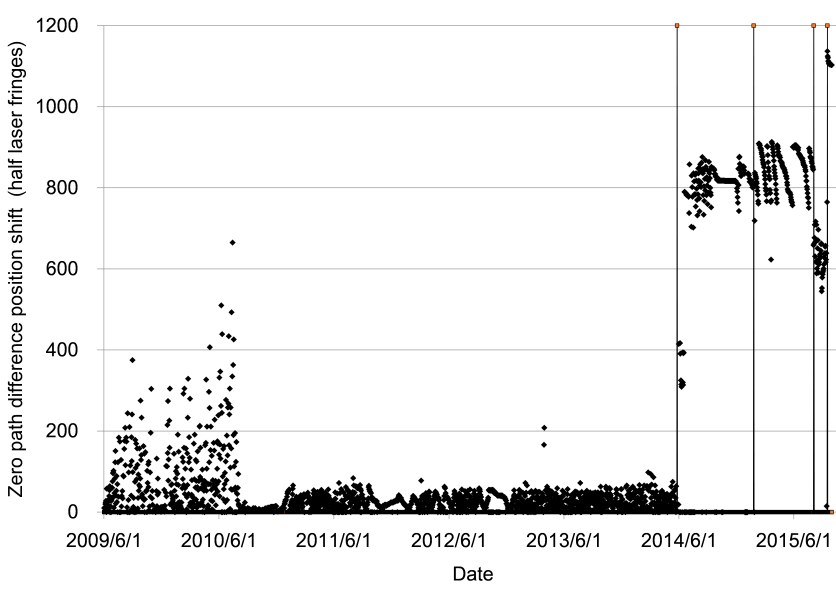

Figure 2. Long-term ZPD position from the center of the interferogram with periodic correction operations. The optical center of the interferogram is 38273 half laser fringes. The vertical lines represent the time of three major system anomalies: solar paddle, pointing mechanism change, and cryocooler suspension and restart.

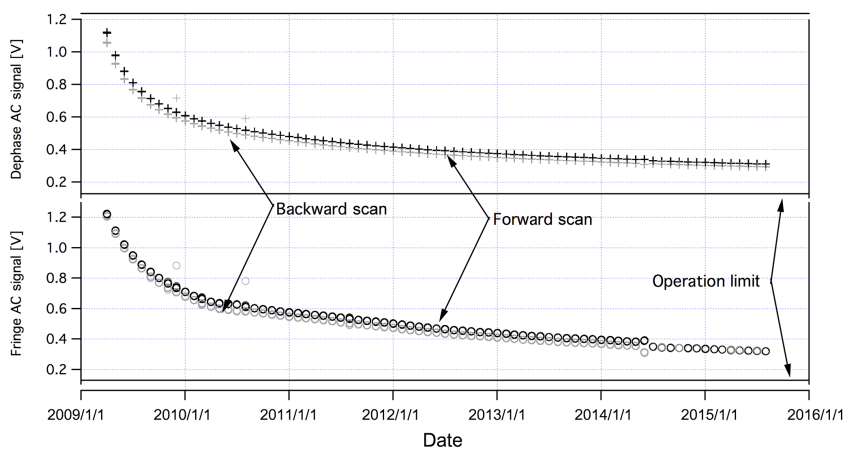

Figure 3. Detected laser signal amplitude of dephase and fringe and the minimum level of $0.13 \mathrm{~V}$ (solid level) to control the FTS mechanism.

electronics. The GOSAT computer automatically shut down both TANSO-FTS and CAI. Since the incident, the combination of one rotating and one non-rotating panel has been generating enough power to operate both TANSO-FTS and CAI. From 30 May 2014, TANSO-FTS and CAI restarted their observations and are now in full operation. However, the FTS ZPD shift has become much faster than before. The most probable cause is a permanent alignment change in the laser detection optics for the fringe channel after the sudden cooldown, resulting in a large decrease in signal level on one side of the FTS scan. The FTS scan controller has become more sensitive to micro vibrations. By biasing more than 800 half laser fringes to the side with a higher laser detection level, the ZPD shift becomes much slower but all the data have a ZPD position too far from the center of the interferogram requiring asymmetric weighting function processing. Regardless of the biased ZPD position, the radiometric response and spectral positions remain unchanged. After the incident, all the L1B 


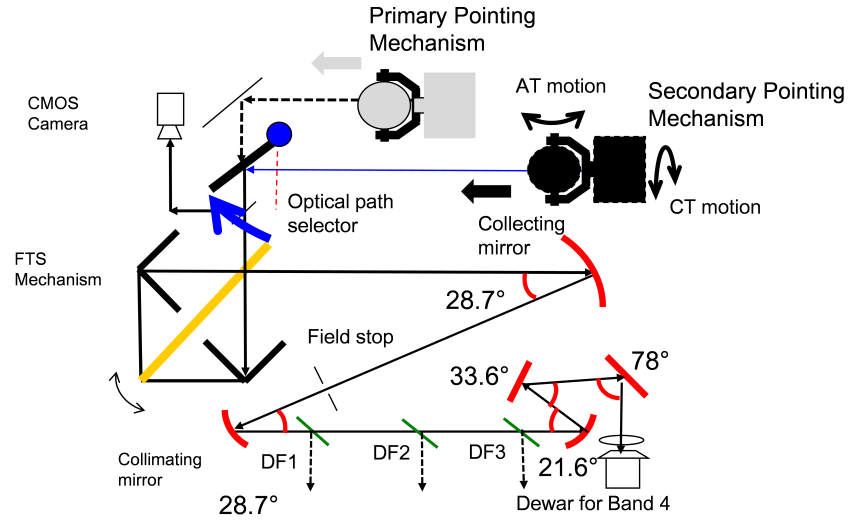

Figure 4. Pointing mechanisms and optics layout of TANSO-FTS.

data have quality alert flags indicating a ZPD bias larger than 100 half laser fringes. In addition, scans with large ZPD shift from the center of the acquired interferogram have caused false alert flags as the center burst was detected as a pointing fluctuation. Scans with large ZPD shifts suffer from resolution degradation when processed with L1B V161. To accommodate this change for V161, the Japan Aerospace Exploration Agency (JAXA) is providing the modified instrument line shape function (ILSF) for single-side-biased interferograms.

\subsection{Pointing instability and switch to secondary mechanism}

A two-axis pointing system is used by TANSO-FTS to allow both CT and AT motions. In the typical three-point CT scan mode, the AT mechanism provides slow image motion compensation during each $4 \mathrm{~s}$ integration for $40.8 \mathrm{~s}$ and quick turnaround and return of $0.6 \mathrm{~s}$ with $\pm 6^{\circ}$ mechanical swing motion. Since 3 September 2014, the settling time of the AT pointing of the primary system worsened, resulting in an error greater than $0.1^{\circ}$ at the beginning of interferogram acquisition. A parameter tuning of the pointing control on 17 November 2014 did not remedy the problem and the pointing stability continued to decay. Realizing that the primary pointing mechanism might be degraded due to aging of the ball bearings and lubricant, the secondary system was characterized and calibrated over the following one and a half-month time period. During this time (since 15 December 2014), the L1B processing was suspended and all the target mode observations were canceled. On 26 January 2015, the pointing was switched from the primary pointing system to the secondary system by rotating the optical path selector by $45^{\circ}$ as shown in Fig. 4. The pointing settling and stability then became smaller than $0.1^{\circ}$, which is much better than the primary system. The nominal observations with glint and target were then restarted and the AT motor traveling range is once more $\pm 20^{\circ}$ with no angular offset. From 30 August 2015, the target mode planning system was re- sumed allowing users to specify targets of interest with accurate geolocation correction.

The TANSO-FTS engineering model (FTS-EM) was operated in a vacuum chamber on the ground to investigate the pointing system behavior after switching to the secondary mechanism. Under vacuum, the stiffness of the cable twisting is increased, resulting in reduced AT traveling range. The secondary pointing system indicates cable hardening but the level is much smaller than the primary system. We repeated the hardening both with the FTS-EM mechanism and new cables. Once activating the swing motion in the vacuum and air, the cable shows hardening and softening but no change without motion. Two cycle tests showed that continuous motion changes the stiffness. The data also showed the saturation of the hardening after a week-long operation. The hypothesis is that oxidization of the metal cable smooths the swing motion in the air. The ground test result suggests that the secondary pointing system may continue with stable motion in orbit. Once cable hardening is detected, the AT traveling range will need to be reduced as was done for the primary pointing system.

Lessons learned from the operation with the primary pointing system show that the use of wider AT motion with a larger ball bearing rotation can minimize aging effects. In parallel, we have started a periodic diagnostic operation to monitor the cable stiffness and the friction of lubricant and bearing by using full range of AT motion every 3 days. Except for the initial change in December 2014 and January 2015, the secondary pointing mechanism shows no significant change in the cable stiffness and friction of the lubricant. Therefore, there is no need to reduce the range of the secondary system AT pointing.

The AT angular resolver shows AT angle errors larger than $0.1^{\circ}$ (sometimes $1^{\circ}$ ) especially when GOSAT passes over certain areas. These phenomena suggest that angular sensors and readout cables are sensitive to electromagnetic interference. To minimize mechanical shock to the AT pointing mechanism, since 30 August 2015 the secondary pointing system is stopped for a short time of less than 1 min over certain areas while keeping the FTS mechanism activated.

\subsection{Cryocooler shutdown and temporary TANSO-FTS band 4 TIR suspension}

On 2 August 2015, TANSO-FTS-TIR (band 4) suspended its data processing due to a sudden shutdown of the cryocooler. The temperature of the band 4 detector increased from $70 \mathrm{~K}$ to ambient temperature, while the shortwave infrared (SWIR) bands 1, 2, and 3 were operating normally and providing $\mathrm{O}_{2}, \mathrm{CO}_{2}$, and $\mathrm{CH}_{4}$ spectra. The most probable root cause is a single event anomaly on the cryocooler control electronics. After the sudden cryocooler mode changed to standby, probably because of the rapid change in thermal balance, the ZPD position of the interferogram shifted rapidly from 800 half laser fringes, crossed the center of the 
scan, and then shifted to 650 fringes on the opposite side of the center of the scan. The ZPD shift mechanism is complicated and it is difficult to simulate the thermal distortion without the large heat source of the cryocooler. For 6 weeks, the bias value of 650 half laser fringes showed a stable condition. The new L1B V201 is able to correct the 650 half laser fringes-biased interferogram properly. On 14 September 2015, the cryocooler was restarted successfully. The new ZPD stable position after the cooler restart is 1100 half laser fringes, which is on the same side but slightly larger bias than before 2 August. After 15 September, both SWIR and TIR have been acquired simultaneously with nominal grid, target, and glint modes. As Fig. 3 presents, the lower detection level in the future might require a larger ZPD bias to decrease the ZPD shift.

\subsection{Calibrations}

\subsubsection{Radiometric calibration: response degradation}

Analytical results from the annual vicarious calibration campaigns (VCCs) in Railroad Valley (RRV), Nevada, USA, and monthly on-orbit solar diffuser calibrations show that the absolute radiometric response for both TANSO-FTS-SWIR and TANSO-CAI had rapid initial degradation for the first 2 years, followed since by slower degradation (Kuze et al., 2011; 2014). The relative changes in TANSO-FTS, estimated from the backside diffuser calibration, are now very slow as shown in Fig. 5. The degradation rate is slightly higher for the $S$ polarization than for the $P$ polarization in band 1 . The most probable source of the degradation is the FTS beam splitter efficiency. After correction of the Spectralon diffuser bidirectional reflectance distribution function (BRDF) and the distance from the sun, the seasonal variation remains. Possible causes are the temperature-dependent band 1 modulation efficiency, imperfect Spectralon BRDF correction, and earthshine contamination (Toon et al., 2015). The prelaunch data show a temperature dependency in the modulation efficiency. Twice every year, in April or May, and just after the summertime VCC, lunar calibrations have been conducted for both TANSO-FTS and CAI by rotating the satellite and tracking the lunar surface. Except for the sixth lunar calibration on 15 July 2011, TANSO-FTS successfully targeted the lunar disk within the instantaneous field of view (IFOV). The phase angle of the moon was within $2-5^{\circ}$ of full moon phase for the first four calibrations but was changed to around $7^{\circ}$ for 2010 as the lunar BRDF changes rapidly near the full moon. After the solar paddle anomaly, the lunar calibration was suspended to avoid the extreme power consumption of the batteries. The lunar radiometric calibration is consistent with the VCCs within their respective error budgets (Shiomi et al., 2013).

Since the work published in Kuze et al. (2014), annual VCCs were also performed in 2013, 2014, and 2015, and the data were processed using the same method. Figure $6 \mathrm{a}$

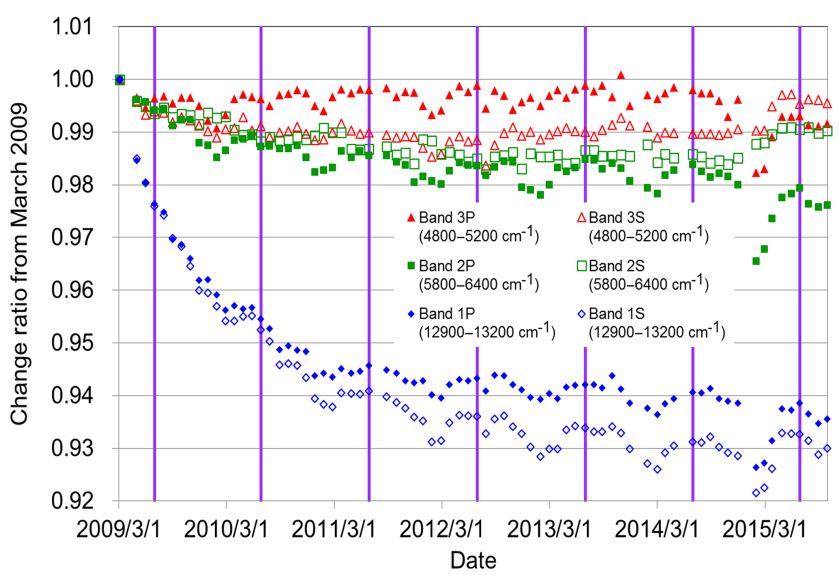

Figure 5. Solar irradiance monthly calibration data from the back side of the onboard Spectralon diffuser, which indicates the change from the first measurement in space after correction for the distance between the satellite and the sun and the angle of incidence of the solar beam upon the diffuser. The vertical lines represent the time of vicarious campaigns.

shows the TANSO-FTS RDF by comparing the measured radiance, using prelaunch radiometric conversion factor, and forward calculation using surface and radiosonde data together with the RDF model described in Kuze et al. (2014). The results show very slow radiance response degradation. In addition, the 2015 VCC shows there is no significant difference between the primary pointing system and the secondary unit. Therefore, there is no need to change the RDF model. These data can be applied to the complete long-term L1B data set. Figure $6 \mathrm{~b}$ indicates no degradation of TANSO-CAI since VCC2011. The error budget of VCC is estimated to be lower than the assigned value of $7 \%$. Inter-comparison with the well-calibrated Visible Infrared Imaging Radiometer Suite (VIIRS) radiometer onboard the Suomi National Polar-orbiting Partnership (SUOMI-NPP) also shows longterm agreement with the TANSO-FTS RDF model within the allocated error budget (Uprety and Cao, 2015).

For TIR calibrations of TANSO-FTS band 4, frequent calibration using the blackbody (BB) and deep space (DS) can remove the response degradation and background radiation. During the VCC2011, the systematic error after calibration in each spectral window was analyzed, showing a higher bias of $2 \mathrm{~K}$ in L1B V130 in radiation from the cold upper atmosphere in the $\mathrm{CO}_{2}$ band at $650-700 \mathrm{~cm}^{-1}$ (Kataoka et al., 2014). The radiometric calibrations are modified in V161 and are described in Sect. 3.1. Long-term comparison with sea surface temperatures monitored by NOAA buoys shows that the difference in monthly means are smaller than $1 \mathrm{~K}$ over 6 years (Kataoka et al., 2015). 
(a)
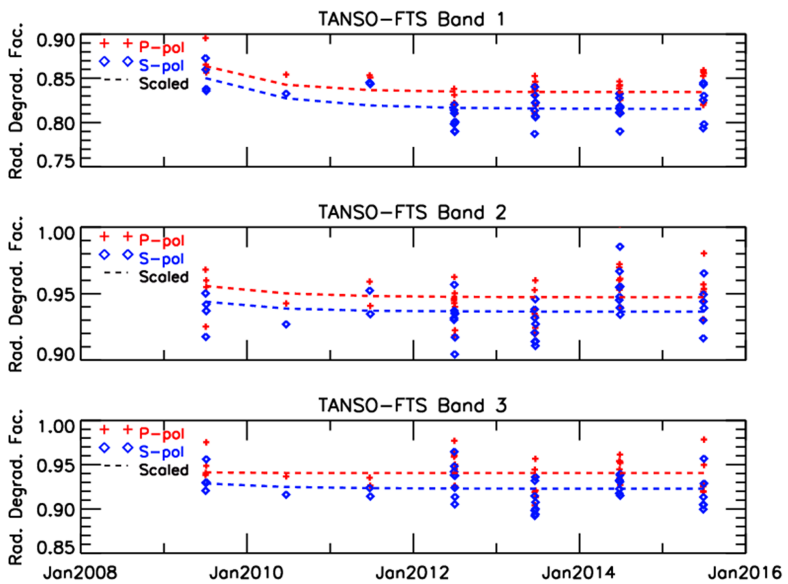

(b)

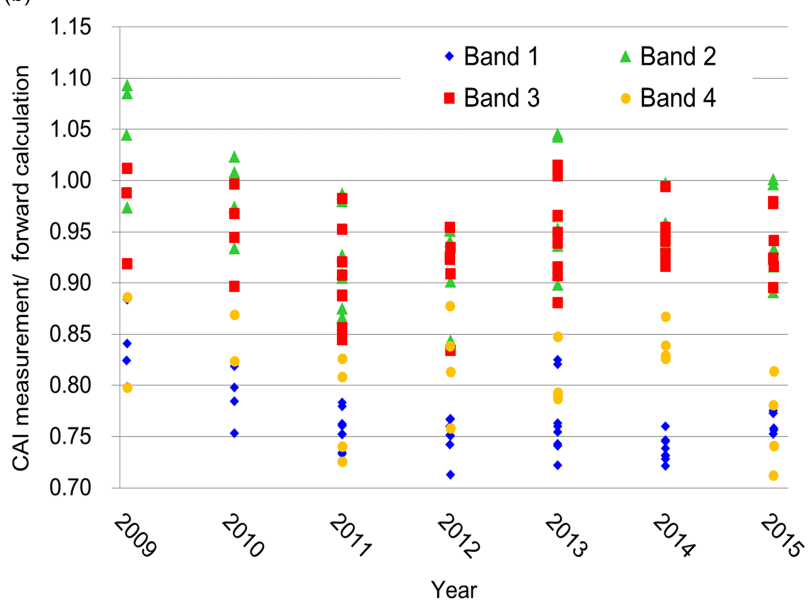

Figure 6. RDF for 6 years from seven annual vicarious calibration campaigns of (a) TANSO-FTS and (b) TANSO-CAI. Each symbol represent calibration points calculated from individual surface measurement. The lines in (a) show the model derived from the onboard solar diffuser data.

\subsubsection{Spectral calibration}

The temperature of the onboard metrology laser in the FTS mechanism has been well controlled for more than 6 years. Except for the very gradual changes described in Kuze et al. (2012), the absolute spectral position using solar Fraunhofer lines and ILSF using the onboard calibration laser indicate very stable spectral characteristics. No correction value has to be considered in the L1B processing and there is no difference between the data from the primary and secondary pointing systems.

\subsubsection{Geometric calibration and target observation planning}

The TANSO-FTS primary pointing system has a pointing offset that cannot be detected with an angular resolver (Kuze

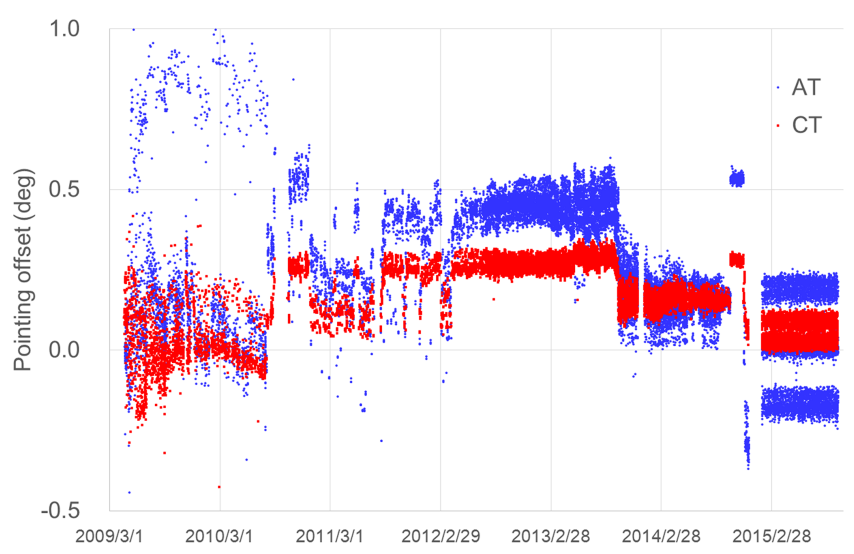

Date

Figure 7. Long-term pointing offset for grid observations: AT optical angle (blue circle) and CT (red square). Since August 2010, the grid observation pattern has changed from the five-point CT mode to the three-point CT scan mode. From 23 January 2015, the secondary pointing system is used.

et al., 2012). The angular telemetry used by geolocation by the L1B algorithm therefore introduces a bias. The pointing offset has been estimated using the onboard camera (CAM). The long-term pointing offset for both grid and target observations is presented in Fig. 7. The offset before January 2015 , changed slowly with a monthly timescale. Every 2 weeks after observation, the best-estimate offset values are updated, and these values are provided to GOSAT data users by the National Institute for Environmental Studies (NIES) via the GOSAT user interface gateway (GUIG). The application of these correction values reduces the fluctuation in the geolocation to less than $1 \mathrm{~km}$. In planning target mode observations, especially of volcano vents and power plants, applying the offset in advance leads to more accurate pointing. Target mode planning has been implementing the pointing offset since 5 August 2013. Target observations are planned 2 weeks in advance, but the pointing correction at the time of the target observation is applied. Generally, with this change plus the above-mentioned fluctuation of $1 \mathrm{~km}$, the target mode observations have been performed with pointing errors less than $2 \mathrm{~km}$.

The pointing offset of the secondary pointing mechanism is different. No offset in the angular resolver has as yet been detected. The pointing settling of the secondary system is much more stable than the primary one. However, the optical path selector shown in Fig. 4 was rotated by $45^{\circ}$ and introduces scene flux as a folding mirror. The axes of the optical path and CT rotation are slightly misaligned, which results in the CT angle-dependent offset. The offset is repeatable and can be well characterized. The L1B V201 product has corrected geolocations, and the accuracy after correction is better than $0.5 \mathrm{~km}$. For target observations, the geometrical offset and misalignment between the GOSAT satellite bus and 


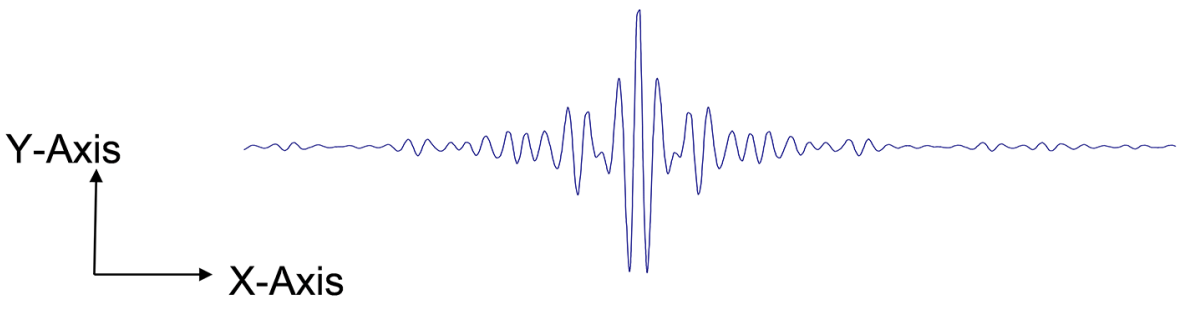

Figure 8. Corrections in the Level 1 B processing in the interferogram domain. V050, V110, V130, V150, V161, and V201 are versions of the Level 1B. The items with italic letters are described in this paper. $X$ axis (re-sampling): (1) FTS mechnism scan speed instability correction for medium gain (2 sinusoidal sources) (V110 and later); (2) sampling interval non-uniformity correction (SINUC) (V150 issue, not applied in V161, modified in V201); (3) analogue circuit intensity dependent phase delay correction (V201); (4) Doppler shift due to image motion compensation (forward to backward viewing) (not corrected). $Y$ axis (intensity correction): (1) intensity variation (low frequency) component correction (V050, modified in V201); (2) Band 4 detector nonlinearity correction (V110 and later, to be modified in the next version); (3) Band 1 high gain amplifier nonlinearity correction (V150, modified in V201); (4) ADC nonlinearity (not corrected, V130 issue).

TANSO-FTS has been implemented from 30 August 2015. At this time, there is no need for additional correction using the CAM data.

\section{Updates to Level 1 products}

\subsection{Issues in previous versions and L1B V161 modifications}

The V150 L1 algorithm is described in detail by Kuze et al. (2012) and Suto et al. (2013a). Two significant modifications to L1B V161 are described here. First, the optical path difference (OPD) sampling interval nonuniformity correction (SINUC) as described in Sect. 2.3.5 of Kuze et al. (2012) was applied in L1B V150. However, a spectral ringing artifact was inadvertently introduced to the spectra in the L1B V150 processing, as 100 zeros were filled in at both ends of the interferogram. The L1B V161 processing switched off SINUC to correct this mistake.

The second significant change to the L1B V161 product is related to the TANSO FTS thermal infrared measurement in spectral band 4 . The TIR radiometric validation, performed via comparisons with other satellite and airborne instruments such as the Scanning High-resolution Interferometer Sounder (S-HIS), indicates that the strong $\mathrm{CO}_{2}$ absorption band at $660-700 \mathrm{~cm}^{-1}$ has a high bias (Kataoka et al., 2014). This suggests that the DS obscuration correction applied in L1B V130 and V150 overcorrected the longwave spectra. Further analysis indicated that the DS view obscuration is unrealistic, given the mechanical alignment and pointing offset described in Sect. 2.5.3. For the polarization sensitivity correction, we had applied a polarization incident angle of $45^{\circ}$, which was measured prelaunch, for all of the reflecting surfaces. However, some of the mirror surfaces have angles of incidence less than $45^{\circ}$ as indicated in Fig. 4. For L1B V161 and later, a more accurate polarization reflectance for each mirror was applied by interpolating between discrete reflectance models with incident angles of 35,45 , and $55^{\circ}$. This application improves longwave radiometric calibration and the DS view correction is no longer applied. Other minor modifications include estimating the direct current (DC) offset by preparing long-term look-up tables with very small gradual time dependence and implementing BB temperature conversions using fine-step look-up tables instead of interpolating discrete prelaunch calibration data.

\subsection{L1B V201}

In this section, the most recent L1B V201 is described. There are three major objectives for this update: modifying band 1 nonlinearity correction, creating a data product that accurately accommodates the two major anomalies in 2014, and adding information for users' convenience. Nonlinearity introduced by the band 1 analogue signal chain has been a long-term issue for the L1B processing (Suto et al., 2013a, b). First, we address the radiance spectra improvement by correcting the nonlinearity in the interferogram domain via intensity-dependent phase correction ( $x$ axis) in addition to an amplitude correction ( $y$ axis), as shown in Fig. 8. Then, we describe the reprocessing of the more than 6 years data set using the same spectral resolution after correction of the large ZPD shift caused by solar paddle incident and the other corrections. The updated data flow, including modified processing, is shown in Fig. 9. As the ZPD position is largely shifted, the L1B V201 algorithm detects the ZPD position before qualification and correction procedures.

\subsubsection{Band 1 nonlinearity and intensity-dependent phase correction}

By carefully analyzing more than 6 years of on-orbit data, we revised the nonlinearity corrections based on the prelaunch test and the tests with the EM in the laboratory after launch. As the Fourier transform spectrometer is based on the linear response of the instrument, the linearity of the detector, 


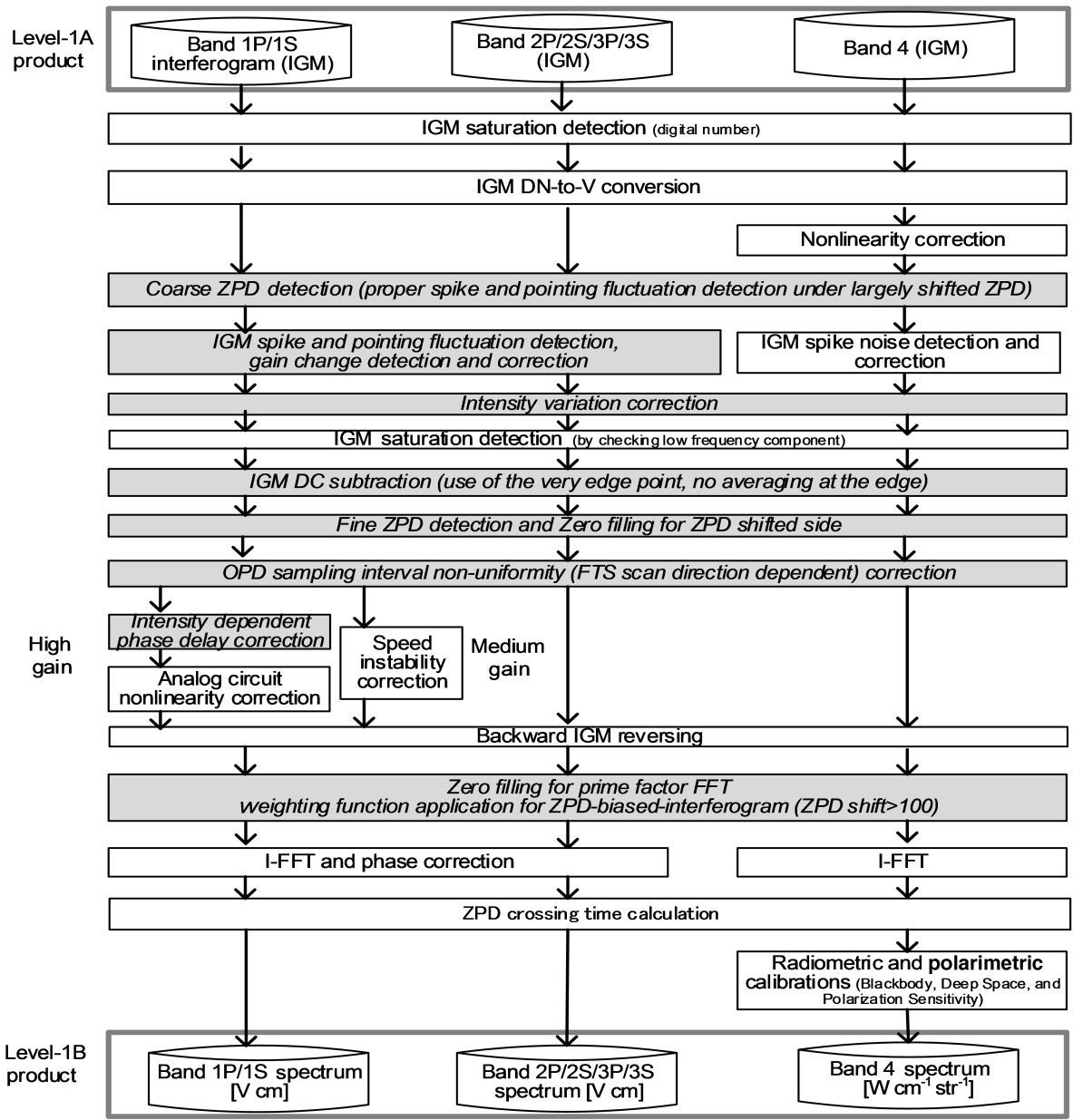

Figure 9. TANSO-FTS L1B V201 data processing flow. Hatched boxes and italic letters show the modification from L1B V161. The procedures are also modified in L1B V201.

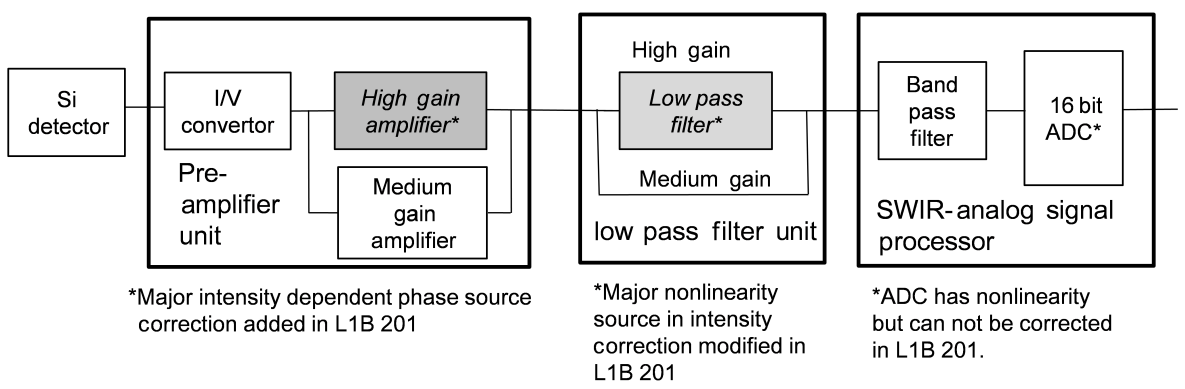

Figure 10. Band 1 analogue circuit block diagram and correction in L1B V201.

electric parts, and integrated circuit in the analogue signal processing chain have to be carefully investigated. All the nonlinear items in the analogue circuits (amplifier, electrical filter, and detector) are corrected in the interferogram domain, as presented in Fig. 8. No corrections were performed in the spectral domain. The identified nonlinear parts of the band 1 analogue circuit are shown in Fig. 10. The oxygen A $\left(\mathrm{O}_{2} \mathrm{~A}\right)$ band in band 1 is used to estimate the effective light-path length with modification by scattering. Band 1 also covers solar Fraunhofer lines. The nonlinearity corrections directly improve the Level $2 \mathrm{X}_{\mathrm{CO}_{2}}$ and $\mathrm{X}_{\mathrm{CH}_{4}}$ products and chlorophyll fluorescence retrieval. Earlier versions of the band 1 nonlinearity correction was applied in L1B V150 and V161. Assuming that the nonlinearity in the band 1 analogue circuit mainly occurred in the low-pass filter circuit, it can be expressed as a single set of third-order polynomials and 


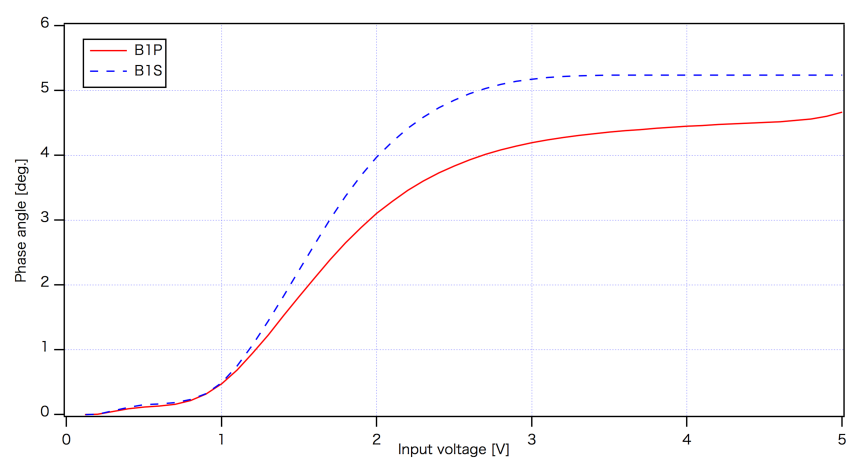

Figure 11. Intensity-dependent phase of the band $1 P(\mathrm{~B} 1 P)$ (solid line) and $S(\mathrm{~B} 1 S)$ (dotted line) high gain analogue circuit. Higher gain $\mathrm{B} 1 S$ has larger dependency.

corrected (Suto et al., 2011). However, both gain amplifier and the low-pass filter circuit have nonlinearity with different characteristics. It was found that the nonlinearity correction could not remove input-level-dependent offset and outof-band artifacts completely.

As shown in Fig. 10, the actual analogue circuit consists of four sub modules: the silicon $(\mathrm{Si})$ detector, the high gain amplifier, the low-pass filter, and the analogue to digital converter (ADC). The Si detector is highly linear. The ADC nonlinearity is difficult to correct as discussed in Kuze et al. (2012). After the release of L1B V150 and V161, we measured the intensity-dependent phase delay in the high gain amplifier circuit using the EM in the laboratory (Suto et al., 2014). The phase delay of the in-orbit circuit should be close to the EM value but needs to be estimated by finding the parameters that minimize out-of-band spectra. The estimated input-dependent phase is shown in Fig. 11. These phases are corrected separately by resampling the interferogram in L1B V201, while in V150 and V161 these phases in the high gain amplifier and amplitude nonlinearity in the low-pass filter are simultaneously corrected by using a single set of third-order polynomials. As the phase is an $x$ axis error in the interferogram, a separate correction is more appropriate. This correction has been implemented in L1B V201. The nonlinearity correction parameters were almost constant but might have small variation. Therefore, multiple iterations are applied as shown in Fig. 9.

\subsubsection{Large ZPD biased interferogram correction}

A large ZPD shift causes a change in spectral resolution since the interferogram has fewer samples on one side of the ZPD than on the other side. To provide precisely uniform resolution data for the entire mission, a ZPD bias correction is applied to produce the full spectral resolution data from the biased ZPD interferogram as illustrated in Fig. 12. The biased interferogram is multiplied by the weighting function and Fourier-transformed using the same length as a normal interferogram. The smooth weighting transitions at the edges

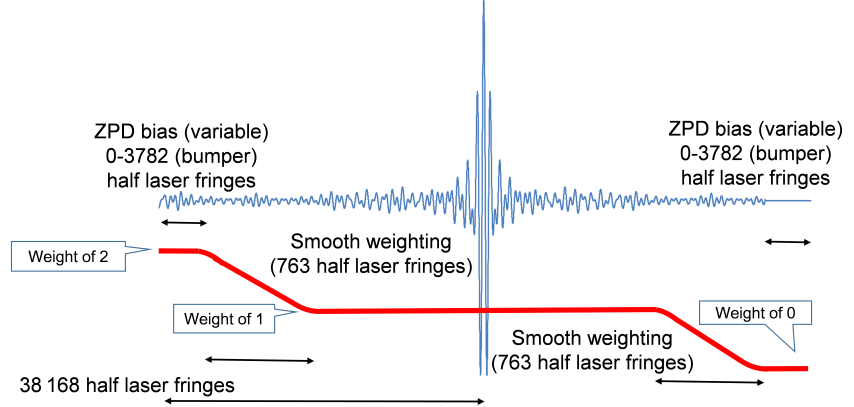

Figure 12. Weighting function for interferogram with bias larger than 100 half laser fringes.

are used to limit the artifacts to a very low frequency out of band region. The regions where the weight is 2 or 0 varies with the ZPD bias, which is calculated for every interferogram as illustrated in Fig. 9. The largest bias value is 3782 half laser fringes, when the FTS mechanism hits the bumper. When the ZPD shift is less than 100 half laser fringes, no weighting function is applied. After June 2014, almost all the data are processed with a weighting function resulting in a slight reduction of the signal-to-noise ratio (SNR) as the number of total sampling points per interferogram is reduced by the bias value. The constant ILSF can be applied to all the L1B V201 products. The ILSF model for V201 is provided from NIES GUIG.

\subsubsection{Corrections for intensity variation and sampling interval nonuniformity}

Intensity variation is corrected by dividing the interferogram by an interferogram created from the low-frequency components such as pointing fluctuation and optical vignetting. During normalization, we used the linear slope of the DC component for L1B V201 instead of a boxcar DC component used in previous versions. After the intensity variation correction described in Kuze et al. (2012), the interferogram became symmetric and both edges have almost the same signal levels. Up to L1B V161, the DC level is subtracted by the linear slope obtained by averaging the 100 edge fringes at both ends of the interferogram. This process sometimes creates artifact spectra from linear slope components. For L1B V201, the DC level is subtracted by using a single point at the edge instead of averaging 100 fringe values. The V201 L1B algorithm applies SINUC again by modifying the sampling interval nonuniformity model in Fig. 5 in Kuze et al. (2012) to have smooth ends at the maximum OPD. This correction improves the consistency between the forward and backward scanning and removes the ringing artifact structure that existed in V150. 


\subsection{Information added to L1B V201}

After more than 6 years of operation, data processing, and data distribution, there have been many questions and comments from GOSAT users. The answers to frequently asked questions and important and useful ancillary data have been added to the L1B product itself. The modified items are described in the following subsections.

\subsubsection{Master quality flags}

Before launch, quality flags of possible anomalies were prepared, but most of the anticipated anomalies never occurred in orbit or remained below the criteria because the temperature of the optics and detectors have been well controlled, and scan speed instability of the FTS mechanism is much less than $2 \%$. These flags have been removed from the L1B V201 products. Only the pointing fluctuation and saturation cause quality degradation. A newly introduced master quality flag identifies poor interferograms resulting from fluctuating pointing. As the data are identified from the measured modulated data, the flag cannot detect poor interferograms when fluctuation occurs near the center burst of the interferogram and the surface reflectance is spatially uniform. The ratio of poor data is about $10 \%$ and most of the fluctuating data are filtered out.

\subsubsection{Calibration information}

A number of new items have been added to the L1B V201 product data to provide advanced analysis and for users' convenience.

i. Best-estimate pointing location: although the pointing offset is considered in planning the target mode observation, the geolocation calculated from the angular resolver and satellite position data has a pointing offset as described in Sect. 2.3 and summarized in Table 1; the best-estimated pointing locations are added. The pointing offset is now provided in the L1B V201.

ii. Best-estimate radiance conversion for SWIR (bands 1, 2, and 3): the spectral radiance data, given in units of volt $\mathrm{cm}(\mathrm{V} \mathrm{cm})$, have been converted to the calibrated spectral radiance given in units of $\mathrm{W} \mathrm{cm}{ }^{-1} \mathrm{str}^{-1}$ using the prelaunch calibration data. The degradation after launch is also corrected using RDF provided in Kuze et al. (2014).

iii. Finite-size IFOV correction for TIR (band 4): the finite size of the field of view has a self-apodization effect. Without large degradation of the spectral shape, the selfapodization due to the size is corrected as described by Knuteson et al. (2004). Together with the original radiance spectra for atmospheric molecules retrieval, the corrected spectra for band 4 are added for meteorological applications. iv. Mueller matrix for utilizing two linear polarization data: for SWIR, the input solar scattered light is measured in both $P$ and $S$ polarizations separately. The overall optical efficiency of the two linear polarizations, which are combinations of the pointing mirror, the FTS beam splitter, and the aft-optics, differs slightly with pointing angles. Therefore, the instrument polarization of both optical efficiency and phase can be characterized for wide spectral range with a Mueller matrix (Kuze et al., 2012; O'Brien et al., 2013). The pointing mirror portion of $\mathbf{M}\left(\theta_{\mathrm{AT}}, \theta_{\mathrm{CT}}\right)=$ $\mathbf{M}_{\boldsymbol{r}}\left(-\theta_{\mathrm{CT}}\right) \mathbf{M}_{\boldsymbol{p}}\left(\theta_{\mathrm{AT}}\right) \mathbf{M}_{\boldsymbol{m}}\left(\theta_{\mathrm{AT}}\right) \mathbf{M}_{\boldsymbol{r}}\left(\theta_{\mathrm{CT}}\right)$ in Eqs. (9) and (10) of Kuze et al. (2012) is a function of pointing angles and varies in every measurement. The calculated value for each measurement from the mirror surface reflectivity and its phase is stored in the L1B product later than V201 for users' convenience. As a degradation correction can be applied to the radiance calibration portion, the degradation is not included in Mueller matrix.

v. CAM data with joint photographic experts group (JPEG) format: the onboard CMOS camera shown in Fig. 4 is mounted on the optical axis of the TANSO-FTS and can identify the location viewed by the FTS pointing mechanism. CAM has a much higher spatial resolution than TANSO-CAI and is useful for cloud screening. CAM was originally designed to check the optical alignment after launch. It has been working without degradation beyond its designed life of 1 year. On the day side, we have been acquiring CAM data every $4 \mathrm{~s}$ and at least one CAM image exists per interferogram. One CAM image is selected and attached to the L1B showing the exact pointing location.

vi. Scattering angle: surface reflection and scattering from aerosol and clouds have a strong dependence on geometry. The scattering angle is the angle between the incident sunlight direction and scattered light toward GOSAT. It can be calculated from the sun and satellite positions and pointing angles. This value has been added to the L1B V201 for the users' convenience.

vii. Target mode classification: calibration and validation sites, large emission sources, and volcanos have been targeted in addition to the nominal grid observations. To avoid large biases in $\mathrm{X}_{\mathrm{CO}_{2}}$ and $\mathrm{X}_{\mathrm{CH}_{4}}$ due to these targeted enhanced emission sources, target observations are categorized and identified so that they may be screened out by the user.

viii. A brief comment as a long name for Hierarchical Data Format (HDF) viewer: TANSO-FTS is a unique instrument compared to conventional imagers, and some parameters in L1B are specific and not easily understood by users. Brief explanations of the parameters are added as a long name. 
Table 1. Pointing offset and geolocation information in the L1B product.

\begin{tabular}{|c|c|c|c|c|c|}
\hline \multirow{2}{*}{$\begin{array}{l}\text { Pointing } \\
\text { system }\end{array}$} & \multirow[t]{2}{*}{ Pointing offset } & \multicolumn{2}{|c|}{ L1B V161 and earlier } & \multicolumn{2}{|c|}{ L1B V201 } \\
\hline & & Geolocation & Correction & Geolocation & $\begin{array}{l}\text { Best-estimate } \\
\text { geolocation }\end{array}$ \\
\hline $\begin{array}{l}\text { Primary } \\
\text { (PM-A) }\end{array}$ & $\begin{array}{l}\text { Time dependent (correction } \\
\text { table of every } 2 \text { weeks) } \\
\text { (AT and CT angles } \\
\text { independent) }\end{array}$ & Not corrected & $\begin{array}{l}\text { Users have to } \\
\text { use the } \\
\text { correction table } \\
\text { provided from } \\
\text { NIES GUIG }\end{array}$ & Not corrected & Corrected \\
\hline $\begin{array}{l}\text { Secondary } \\
\text { (PM-B) }\end{array}$ & $\begin{array}{l}\text { Constant since February } 2015 \\
\text { CT angle dependent }\end{array}$ & Not corrected & & Corrected & $\begin{array}{l}\text { Corrected } \\
\text { (The same as the } \\
\text { geolocation) }\end{array}$ \\
\hline
\end{tabular}

\subsection{Remaining issues with the V201 product after calibration}

The goal of the calibration and correction is to remove systematic errors. Although major issues in L1B have been solved in the V201 product, there remain systematic errors equivalent to the random noise level. Both SWIR and TIR have possible sources of systematic residuals between the measured spectra and forward calculations.

\subsubsection{SWIR}

The SWIR prelaunch calibrations consisted of $5 \mathrm{~nm}$ steps radiance conversion tables for band 1 and $20 \mathrm{~nm}$ steps for bands 2 and 3. After launch, the vicarious calibration uses $1 \mathrm{~nm}$ step data but the accuracy is worse than the prelaunch calibration. Finer spectral structure in the radiometric response and their changes, as well as calibration uncertainty in the spectral structure, cause the residual bias. Studies have shown that shorter wavelengths within a band have larger degradation, especially in bands 1 and 2 .

As described in Sect. 3.2.1, nonlinearity parameters are selected by minimizing out-of-band artifacts. Real noise and small side lobes are corrected toward zero, and nonlinearity may be overcorrected. At present, it is difficult to accurately extract out-of-band artifacts smaller than random noise. As described in Sect. 2.3.2 of Kuze et al. (2012), the 16 bit ADC used in TANSO-FTS have the largest nonlinearity at the center of the dynamic range. The level of the AC-coupled band 1 interferogram is close to zero volts as the OPD increases, especially in the low input cases of dark scenes. The frequent use of the center bit creates nonlinearity, but there is no correction method at present.

\subsubsection{TIR}

Figure 13 shows the total estimated calibration uncertainty in cases of typical Earth radiation and ideal BB target of $280 \mathrm{~K}$. Errors in the polarization reflectance, onboard BB emissivity

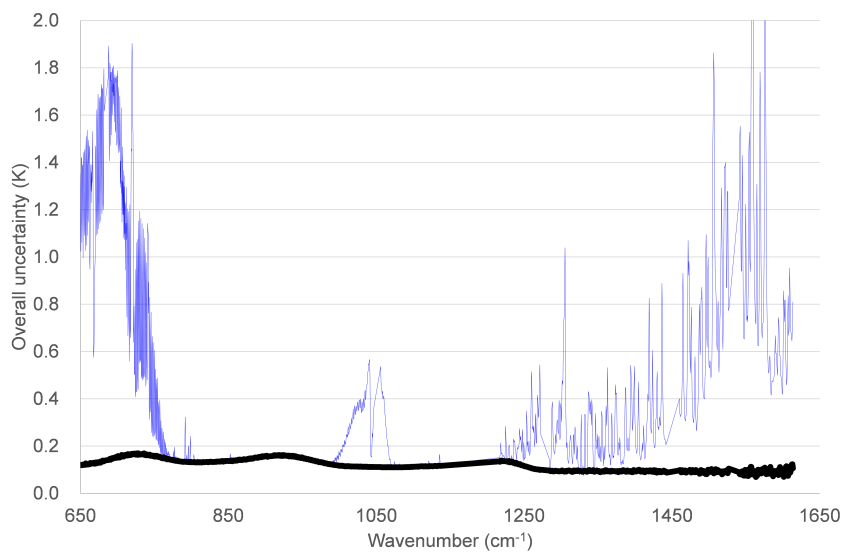

Figure 13. Estimated calibration uncertainty by adding systematic bias error in case of viewing nadir (06:19:10 UTC, on 23 December 2010) (solid line) and $280 \mathrm{~K} \mathrm{BB}$ target (bold line).

measured before launch, and the detector nonlinearity correction coefficient, create systematic errors in the spectral radiance. The measured polarization reflectance has much larger error than the scalar reflectance. The temperature differences between the onboard BB and the environment and between the scene and the mirror surface yield errors. Therefore, when TANSO-FTS views cold atmospheres and surfaces, measurement error is larger than the error from viewing the ideal BB target of $280 \mathrm{~K}$. The polarization correction is one of the largest error sources. To validate the radiometric calibration and polarization correction, High-performance Instrumented Airborne Platform for Environmental Research (HIAPER) Pole-to-Pole Observations (HIPPO) and NOAA buoy data are used as input for forward calibration. In addition, coincident flight data of the airborne S-HIS FTS over Greenland (cold target) and over Railroad Valley (hot target) are used for spectral radiance comparisons. These results suggest the L1B V201 data have spectrally dependent bias equivalent to random noise level. The next L1B version will 
minimize these systematic errors. Meanwhile, we suggest the following bias corrections. The errors are correlated with the background temperature change. The onboard BB temperature with three high-resolution thermometers represents the seasonal and orbital-phase variation in instrument environment temperature. The FTS mechanism and aft-optics on the optical bench are temperature controlled at $23^{\circ}$. The difference between the environment temperature and the optical bench creates a calibration error. Therefore, the following correction can minimize the bias over the wide target temperature range:

$R_{\mathrm{corr}}=R_{\mathrm{obs}}-\left\{a(v) \times\left(R_{\mathrm{obs}}-R\left(T_{\mathrm{bb}}\right)\right)+b(v)\right\}$,

where $R_{\text {corr }}, R_{\mathrm{obs}}$, and $\mathrm{T}_{\mathrm{bb}}$ are corrected and raw observed radiance in $\mathrm{W} \mathrm{cm}^{-1} \mathrm{str}^{-1}$ and $\mathrm{BB}$ temperature, respectively. The scaling factor $a(v)$ and the offset $b(v)$ are both functions of wavenumber $\gamma$, determined from the HIPPO and buoy validation data (Kataoka et al., 2015).

Another issue is the sudden change in TIR signal level, which decreased after the solar paddle incident in May 2014 and increased after the cryocooler shutdown in September 2015. Once the signal level changed, it became stable. As there was no water vapor spectral structure in the difference, the most probable cause is imperfect nonlinearity correction. For the nonlinearity correction, the DC offset level $V_{\text {DCoffset }}$ in the Eq. (1) described in Kuze et al. (2012) has to be carefully tuned as it is estimated from the DS view signal, background radiation model from the optics, and the detector temperature. $V_{\text {DCoffset }}$ is a function with time from launch, which will be modified in the next version. The step change will be removed and the radiometric bias error will be minimized.

\section{Optimizing global coverage}

The nominal sampling strategy of GOSAT TANSO-FTS is a three- or five-point CT scan, along with some special target points such as calibration and validation sites and emission sources. In this section, we discuss ideas and plans for optimizing the usefulness of the GOSAT data collection via changes to the sampling pattern. Some of these ideas could be extended to the planned GOSAT- 2 mission, which is tentatively scheduled for a 2018 launch (Suto et al., 2013b), and the planned OCO-3 mission with a pointing mirror assembly (Eldering et al., 2013).

The two-axis pointing was originally designed for viewing onboard calibration sources and grid point observations. With daily operation planning, the full use of onboard memory in the pointing mechanism controller can be utilized to optimize the global pointing. The agile pointing system permits a large number of custom targets per orbit at the expense of spatial context. It is still difficult to cover the Earth's entire surface with high spectral resolution spectrometers such as OCO-2 and TANSO-FTS, which have 16- and 3-day ground track repeat cycles, respectively. Therefore, a sampling strategy of these instruments benefits from optimization.

Since August 2010, TANSO-FTS has been operating in a three-point CT scan mode. The exceptions are a one-point CT scan mode between September and December 2014 when the primary pointing mechanism was unstable, and a short period of five-point CT scan mode just after TANSO-FTS operation was reset. Thus, measured points were distributed at even distances. The clear-sky yield rate over cloudy area, such as the Amazon, Southeast Asia, and Central Africa and low surface albedo areas such as snow, ice, bays, and channels, is very low. Areas with thick aerosols such as the Sahara also have larger errors. Now that GOSAT has demonstrated accurate $\mathrm{X}_{\mathrm{CO}_{2}}$ and $\mathrm{X}_{\mathrm{CH}_{4}}$ remote sensing, demand for emission source measurements of megacities, power plants, gas fields, and volcanoes has increased. In addition to grid observations, by uploading the pointing angles from the ground every day, TANSO-FTS can target a maximum of about 1000 points per day.

Dithering over fractional cloud areas and targeting coasts and islands while avoiding bays and channels can increase the yield rate of spectra that provide high-quality Level 2 retrievals. Multi-angle observations with cross-track, forward, nadir, and backward viewing with the two-axis pointing mirror may distinguish aerosol scattering from surface reflection and reduce aerosol-related errors. After the pointing mechanism was switched from the primary to the secondary on 26 January 2015, the secondary shows stable settling and slower cable hardening than the primary system. The optimized target mode allocation can now be considered.

\subsection{Emission source observation}

Turner et al. (2015) has compared North America $\mathrm{CH}_{4}$ emissions between the Emission Database for Global Atmospheric Research (EDGAR) v4.2 model, the 2012 US Environmental Protection Agency (EPA) inventory, and the GOSAT Level 2 products. The analytical results show that the EDGAR and EPA bottom-up inventories underestimate a US anthropogenic methane source. The emissions are highest in the south-central USA, the Central Valley of California, and Florida wetlands; large, isolated point sources such as the US Four Corners also contribute. Compared with $\mathrm{CO}_{2}$, $\mathrm{CH}_{4}$ emissions are not well understood. To this end, the sampling of GOSAT paths 35, 36, and 37 over the west coast of North America have been modified by adding targeting of possible large emission sources. For path 35, TANSOFTS targets coal mining and a power plant at Four Corners. For path 36, TANSO-FTS targets the RRV calibration site three times from the east followed by the Armstrong Flight Research Center (AFRC) and the California Institute of Technology (Caltech), which have Total Carbon Column Observing Network (TCCON) validation sites (Wunch et al., 2011). In addition, the Chino dairy complex is targeted from Path 36. For path 37, which occurs the following day, 

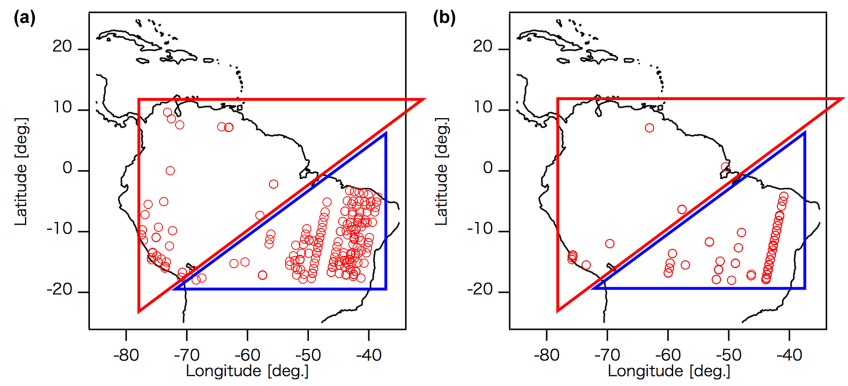

Figure 14. Clear-sky data with (a) and without (b) dithering observation over the Amazon in September 2014. Upper and lower triangles are categorized as tropical rain forest and Cerrado, respectively. The repeated observation location are overwritten.

TANSO-FTS targets RRV three times from the west, then three points near Sacramento, California: rice fields, downtown, and a landfill. Path 37 also samples Bakersfield, California, followed by the AFRC and Caltech sites. For Bakersfield, TANSO-FTS targeted six points per path to include upwind and downwind oil fields together with ground and airborne in situ measurements. This approach, which combines accurate surface, dense airplane, and column measurements, was tested in order to estimate the magnitude of the emissions quantitatively using a chemical transport model, without the need for inversion algorithms (Leifer et al., 2015).

\subsection{Dithering observation in cloudy areas}

In order to understand plant respiration and photosynthesis, we attempt to increase the yield rate of high-quality L1B spectra that yield good Level 2 over the Amazon, which experiences frequent contamination by fractional clouds within the TANSO-FTS $10.5 \mathrm{~km}$ IFOV. Since 2014, for measurements obtained over the Amazon, we tried dithering observations instead of the nominal three-point CT scan mode observation. We simply categorized the region into two areas: tropical rain forest (TRF) and Cerrado (CRD). During the dry season, in September 2014, we applied a 3-day dithering observation after the 3-day no-dithering observation. By filtering out clouds with CAM data, 41 (TRF) and 164 (CRD) data remain with dithering while 23 (TRF) and 163 (CRD) remain without dithering, as illustrated in Fig. 14. This experiment showed that dithering nearly doubled the clear-sky data over TRF during the dry season. Another advantage of dithering is that observation points are increased while a nominal threepoint $\mathrm{CT}$ scan mode is used to observe the same point three times. To provide more statistical analysis, we will continue the dithering observation for selected target regions.

\subsection{Extension of glint observation}

Uncertainty of the $\mathrm{CO}_{2}$ uptake estimation can be reduced by extending the latitudinal range of GOSAT glint measurements over oceans. Due to very low reflectance of water sur- faces, $\mathrm{X}_{\mathrm{CO}_{2}}$ can be retrieved only with glint observation; i.e., in nadir viewing the scene is too dark to provide adequate SNR. Until August 2014, the latitudinal range of glint had been $\pm 20^{\circ}$ of sub-solar point by tracking the exact specular reflection points. Since September 2014, we have extended the glint observation range by tracking not only the exact specular reflection point but also along the principal plane of the GOSAT-sun-specular reflection point on the sea surface. As illustrated in Fig. 15a, at the time of the autumn equinox, the observed range becomes more than $\pm 40^{\circ}$ in latitude by providing additional data beyond $\pm 20^{\circ}$, where the surface reflectance had been too dark to process before. Figure $15 \mathrm{~b}$ shows the clear-sky data point screened with CAM after glint area extension.

\subsection{Multi-angle and slant-viewing observation}

Frankenberg et al. (2012) suggested that it is possible to achieve aerosol-related error reduction using multi-angle measurement with viewing zenith angles of $\pm 30^{\circ}$. Since the AT motion of TANSO is limited $\pm 20^{\circ}$, we have instead measured the RRV vicarious calibration site from the eastern orbit of path 36 and the western orbit of path 37 on the next day. Assuming that the surface and atmospheric condition does not change much within a day, the results can be analyzed statistically. From path 37, the sun is located behind GOSAT with the CT angle of $+33^{\circ}$ producing a scattering angle greater than $150^{\circ}$. In this configuration, GOSAT observes brighter backscattered radiation but, at the same time, the scattering from aerosol and cloud is larger. However, the data from path 36 with the CT angle of $-20^{\circ}$ are less contaminated by aerosol and cloud, which are the largest error sources in the GHG retrieval. At present, we have acquired more than 200 sets of measurements for statistical analysis. These data sets can be used to find the best viewing geometry in the future operation to minimize thin cloud and aerosol contamination.

\section{Summary and Discussion}

Solutions for two GOSAT system anomalies that occurred on-orbit in 2014 have been found and applied to the new L1B V201 processing. Currently, the satellite bus has enough fuel and four healthy batteries for a decade of observations by TANSO-FTS (both SWIR and TIR) and TANSO-CAI. Radiance degradation of TANSO-FTS and CAI has become very slow after rapid degradation for the first 2 years in space. The scanning motion of the TANSO-FTS mechanism has been stabilized by biasing the ZPD position with low metrology laser detection level. Well-calibrated and userconvenient L1B V201 has been released, and the full time series of data (approximately 7 years) is being reprocessed in order to provide the same spectral quality and seamless data. The target mode optimization has improved the number of 
(a)

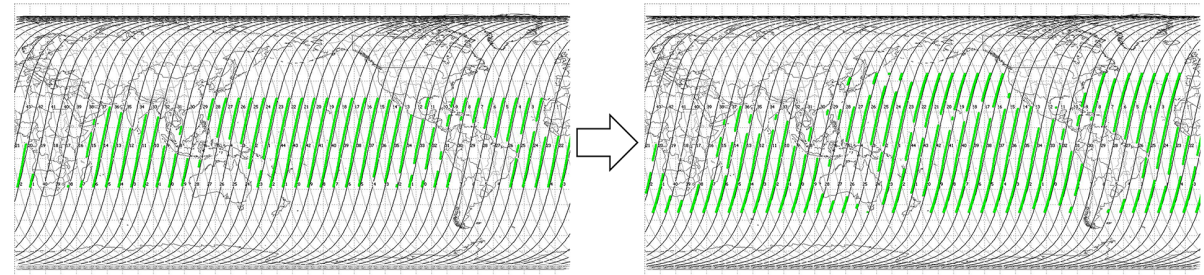

(b)

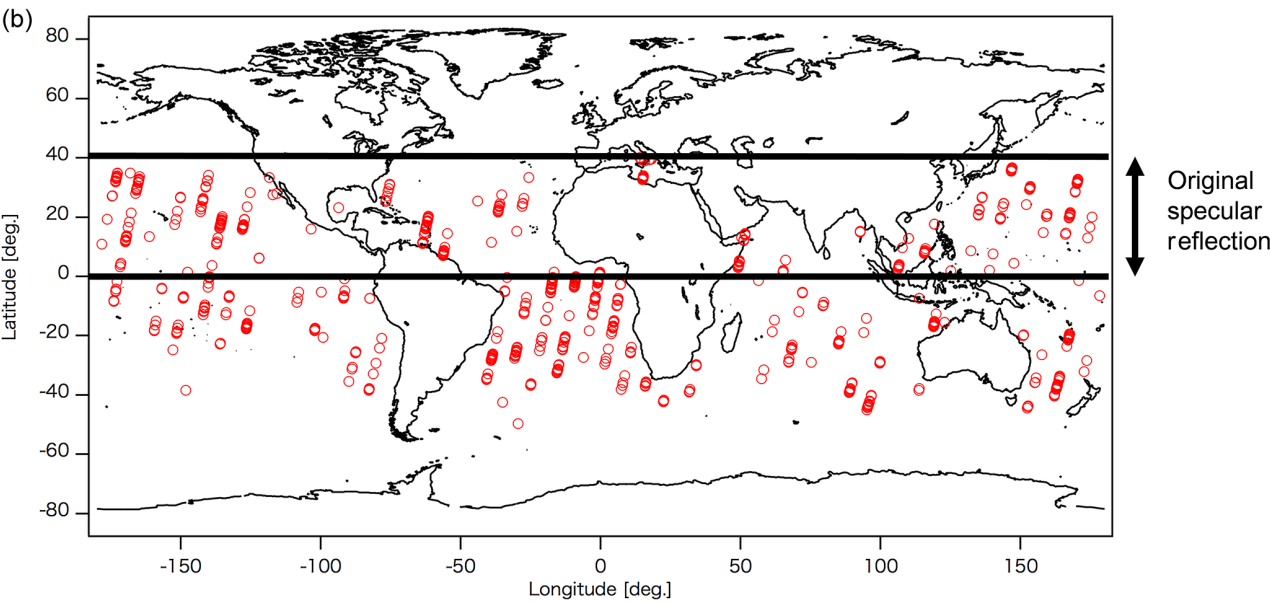

Figure 15. (a) Glint observation area extension by tracking along the principal plane of reflection before (left) and after (right) 10 September 2014; (b) clear-sky data point distribution after extension during 7-9 June 2015.

good data and detected large emission sources, contributing to the effort of detecting emissions using satellite data and understanding missing carbon sinks. Especially with careful operation of the mechanical portions, GOSAT will extend its mission life, maximize TANSO-FTS performance, and provide a unique data set.

Even though the number of sampling points per orbit is smaller than for imaging spectrometers, TANSO-FTS has an advantage of wide spectral coverage for both $\mathrm{CO}_{2}$ and $\mathrm{CH}_{4}$ in SWIR and TIR. OCO-2 uses grating spectrometers, while GOSAT uses a Fourier transform spectrometer to record spectra near $0.76,1.6$, and $2.0 \mu \mathrm{m}$ with different observing strategies, integration times, and spatial and spectral resolutions. With the successful launch of OCO-2 in July 2014, measurements from the two independent instruments can be compared to distinguish common forward calculation errors such as line parameters, aerosol scattering, and ocean glint reflection from instrument-specific errors. The multiplexed and large throughput signal from the FTS requires a larger dynamic range and has a higher possibility of nonlinearity. Grating spectrometers have more complicated instrument line shape functions and pixel-to-pixel nonuniformity. These characteristics have to be properly modeled in the retrieval process. The initial steps of this inter-comparison are (1) radiometric comparison from a common vicarious calibration site at RRV in Nevada, where surface reflectance and BRDF have been characterized over 6 years and $\mathrm{X}_{\mathrm{CO}_{2}}$ data are also available from airborne and ground-based instruments; (2) spectral comparisons from the lunar calibration data; and (3) comparisons of $\mathrm{X}_{\mathrm{CO}_{2}}$ from spatially and temporally coincident observations such as Lamont, AFRC, and Caltech TC$\mathrm{CON}$ sites. Once the two instruments are characterized, they can view common targets from different geometries (Kuze et al., 2015). This capability provides additional constraints on aerosol scattering, which is the largest uncertainty for $\mathrm{CO}_{2}$ retrieval from space.

Globally consistent GHG observation from space is still challenging especially at high latitude and over very bright desert surfaces with thick aerosol. However, a detailed understanding of the carbon cycle requires global satellite data. Further applications, validations, and new algorithms, such as those presented below, should be investigated for full use of GOSAT data.

i. TIR and SWIR synergetic observations: thermal emission from the atmosphere contains vertical density distribution information due to the temperature gradient. With a column density constraint from SWIR, the difference between the upper and lower troposphere can be retrieved, which will contribute to a better understanding of the dynamics.

ii. Simultaneous observation of two liner polarizations: TANSO-FTS is the only space-borne instrument that measures two linear polarizations with high spectral res- 
olution. This capability has the potential to provide improved retrieval of cloud and aerosol (Sanghavi et al., 2015).

iii. Validation with the medium gain: global GOSAT observations cover a wide range of surface albedos (Kawakami et al., 2015). The nonlinearity correction is the most complicated in the L1B processing routine. Except for TCCON at AFRC, all the TCCON sites are located at medium or low albedo areas. Light-path modifications are complicated when aerosols occur over high albedo areas, and hence the retrieval becomes more difficult.

\section{Data availability}

All data sets used here are publicly available and can be accessed through the links and references we have provided.

Acknowledgements. The authors would like to thank J. Katoh, N. Goto, Y. Aketa, S. Funaki, and Y. Tsukahara of the GOSAT operation team; A. Sasaki and S. Obara of the JAXA tribology laboratory; T. Arai of Fujitsu Corporation, K. Ikehara of NEC Corporation; F. Komagata, K. Nakagawa, and T. Hashizume of Mitsubishi Electric Corporation; Y. Yoshida and T. Yokota of the NIES GOSAT team; the JPL OCO-2 calibration team led by C. Bruegge and F. Schwandner; the RemoteC team led by A. Butz at Karlsruhe Institute of Technology; and the SSEC team led by R. Knuteson at the University of Wisconsin. We also thank the Japanese Ministry of the Environment.

Edited by: A. Kokhanovsky

\section{References}

Crisp, D., Atlas, R. M., Bréon, F.-M., Brown, L. R., Burrows, J. P., Ciais, P., Connor, B. J., Doney, S. C., Fung, I. Y., Jacob, D. J., Miller, C. E., O'Brien, D., Pawson, S., Randerson, J. T., Rayner, P., Salawitch, R. J., Sander, S. P., Sen, B., Stephens, G. L., Tans, P. P., Toon, G. C., Wennberg, P. O., Wofsy, S. C., Yung, Y. L., Kuang, Z., Chudasama, B., Sprague, G., Weiss, B., Pollock, R., Kenyon, D., and Schroll, S.: The Orbiting Carbon Observatory (OCO) mission, Adv. Space Res., 34, 700-709, doi:10.1016/j.asr.2003.08.062, 2004.

Crisp, D., Fisher, B. M., O’Dell, C., Frankenberg, C., Basilio, R., Bösch, H., Brown, L. R., Castano, R., Connor, B., Deutscher, N. M., Eldering, A., Griffith, D., Gunson, M., Kuze, A., Mandrake, L., McDuffie, J., Messerschmidt, J., Miller, C. E., Morino, I., Natraj, V., Notholt, J., O’Brien, D. M., Oyafuso, F., Polonsky, I., Robinson, J., Salawitch, R., Sherlock, V., Smyth, M., Suto, H., Taylor, T. E., Thompson, D. R., Wennberg, P. O., Wunch, D., and Yung, Y. L.: The ACOS $\mathrm{CO}_{2}$ retrieval algorithm - Part II: Global $\mathrm{X}_{\mathrm{CO}_{2}}$ data characterization, Atmos. Meas. Tech., 5, 687707, doi:10.5194/amt-5-687-2012, 2012.

Eldering, A., Kaki, S., Crisp, D., and Gunson, M. R.: The OCO-3 mission, AGU Fall Meeting, San Francisco, USA, 9-13 December 2013, A21G-0134, 2013.
Feng, L., Palmer, P. I., Parker, R. J., Deutscher, N. M., Feist, D. G., Kivi, R., Morino, I., and Sussmann, R.: Estimates of European uptake of $\mathrm{CO}_{2}$ inferred from GOSAT $\mathrm{X}_{\mathrm{CO}_{2}}$ retrievals: sensitivity to measurement bias inside and outside Europe, Atmos. Chem. Phys., 16, 1289-1302, doi:10.5194/acp-16-1289-2016, 2016.

Frankenberg, C., Fisher, J. B., Worden, J., Badgley, G., Saatchi, S. S., Lee, J.-E., Toon, G. C., Butz, A., Jung, M., Kuze, A., and Yokota, T.: New global observations of the terrestrial carbon cycle from GOSAT: Patterns of plant fluorescence with gross primary productivity, Geophys. Res. Lett., 38, L17706, doi:10.1029/2011GL048738, 2011.

Frankenberg, C., Hasekamp, O., O’Dell, C., Sanghavi, S., Butz, A., and Worden, J.: Aerosol information content analysis of multiangle high spectral resolution measurements and its benefit for high accuracy greenhouse gas retrievals, Atmos. Meas. Tech., 5, 1809-1821, doi:10.5194/amt-5-1809-2012, 2012.

GOSAT: GOSAT user interface gateway, available at: http://data.gosat.nies.go.jp/GosatUserInterfaceGateway/guig/ GuigPage/open.do, last accessed: 28 May, 2016.

Kataoka, F., Knuteson, R. O., Kuze, A., Suto, H., Shiomi, K., Harada, M., Garms, E. M., Roman, J., Tobin, D. C., Taylor, J., Revercomb, H. E., Sekio, N., Higuchi, R., and Mitomi, Y.: TIR Spectral radiance calibration of the GOSAT satellite borne TANSO-FTS with the aircraft-based S-HIS and the ground based S-AERI at the Railroad Valley Desert playa, IEEE Geosci. Remote S., 52, 89-105, doi:10.1109/TGRS.2012.2236561, 2014.

Kataoka, F., Knuteson, R. O., Kuze, A., Shiomi, K., Suto, H., and Saitoh, N.: GOSAT TIR radiometric validation toward simultaneous GHG column and profile observation, AGU Fall Meeting, San Francisco, USA, 14-18 December 2015, A41I-0165, 2015.

Kawakami, S., Kuze, A., Hillyard, P. W., Podolske, J., Tanaka, T., Iraci, L., Albertson, R., Butz, A., Kataoka, F., Murakami, K., Shiomi, K., Katoh, E., and Suto, H.: A compact automated FTS at the desert playa for satellite validation of the total column $\mathrm{CO}_{2}$ and $\mathrm{CH}_{4}$, Fourier Transform Spectroscopy and Hyperspectral Imaging and Sounding of the Environment, OSA Technical Digest (Optical Society of America, 2015), paper FW3A.2, 2015.

Knuteson, R. O., Revercomb, H. E., Best, F. A., Ciganovich, N. C., Dedecker, R. G. Dirkx, T. P., Ellington, S. C., Feltz, W. F., Garcia, R. K., Howell, H. B., Smith, W. L., Short, J. F., and Tobin, D. C.: Atmospheric Emitted Radiance Interferometer. Part II: Instrument Performance, J. Atmos. Ocean Tech., 21, 1777-1789, 2004.

Kort, E. A., Frankenberg, C., Miller, C. E., and Oda T.: Space-based observations of megacity carbon dioxide, Geophys. Res. Lett., 39, L17806, doi:10.1029/2012GL052738, 2012.

Kuze, A., Suto, H., Nakajima, M., and Hamazaki, T.: Thermal and near infrared sensor for carbon observation Fourier-transform spectrometer on the Greenhouse Gases Observing Satellite for greenhouse gases monitoring, Appl. Opt., 48, 6716-6733, 2009.

Kuze, A., O’Brien, D. M., Taylor, T. E., Day, J. O., O’Dell, C., Kataoka, F., Yoshida, M., Mitomi, Y., Bruegge, C., Pollock, H., Basilio, R., Helmlinger, M., Matsunaga, T., Kawakami, S., Shiomi, K., Urabe, T., and Suto, H.: Vicarious calibration of the GOSAT sensors using the Railroad Valley desert playa, IEEE Geosci. Remote S., 49, 1781-1795, doi:10.1109/TGRS.2010.2089527, 2011.

Kuze, A., Suto, H., Shiomi, K., Urabe, T., Nakajima, M., Yoshida, J., Kawashima, T., Yamamoto, Y., Kataoka, F., and Buijs, 
H.: Level 1 algorithms for TANSO on GOSAT: processing and on-orbit calibrations, Atmos. Meas. Tech., 5, 2447-2467, doi:10.5194/amt-5-2447-2012, 2012.

Kuze, A., Taylor, T. E., Kataoka, F., Bruegge, C. J., Crisp, D., Harada, M., Helmlinger, M., Inoue, M., Kawakami, S., Kikuchi, N., Mitomi, Y., Murooka, J. Naito, M., O’Brien, D. M., O'Dell, C. W., Ohyama, H., Pollock, H., Schwandner, F. M., Shiomi, K., Suto, H., Takeda, T., Tanaka, T., Urabe, T., Yokota, T., and Yoshida, Y.: Long term vicarious calibration of GOSAT sensors; techniques for error reduction and new estimates of degradation factors, IEEE Geosci. Remote S., 52, 3991-4004, doi:10.1109/TGRS.2013.2278696, 2014.

Kuze, A., Shiomi, K., Suto, H., Kataoka, F., Crisp, D., Schwandner, F. M., Bruegge, C., and Taylor, T. E.: GOSAT-OCO-2 synergetic $\mathrm{CO}_{2}$ observations over calibration \& validation sites and large emission sources, AGU Fall Meeting, San Francisco, USA, 1418 December 2015, A41I-0159, 2015

Leifer, I., Melton, C., Tratt, D. M., Kuze, A., Buckland, K. N., Butz, A., Deguchi, A., Eastwood, M. L., Fischer, M. L., Frash, J., Fladeland, M. M., Gore, W., Iraci, L. T., Johnson, P. D., Kataoka, F., Kolyer, R., Leen, J. B., Quattrochi, D. A., Shiomi, K., Suto, H., Tanaka, T., Thompson, D. R., Yates, E. L., Damme, M. V., and Yokota, T.: The relationship between fossil and dairy greenhouse gas emissions and complex urban land-use patterns by in situ and remote sensing data from surface mobile, airborne, and satellite instruments, AGU Fall Meeting, San Francisco, USA, 14-18 December 2015, A11J-0198, 2015.

Lindqvist, H., O'Dell, C. W., Basu, S., Boesch, H., Chevallier, F., Deutscher, N., Feng, L., Fisher, B., Hase, F., Inoue, M., Kivi, R., Morino, I., Palmer, P. I., Parker, R., Schneider, M., Sussmann, R., and Yoshida, Y.: Does GOSAT capture the true seasonal cycle of carbon dioxide?, Atmos. Chem. Phys., 15, 13023-13040, doi:10.5194/acp-15-13023-2015, 2015.

Liu, M., Lei, L., Liu, D., and Zeng, Z.-C.: Geostatistical analysis of $\mathrm{CH}_{4}$ columns over Monsoon Asia using five years of GOSAT observations, Remote Sens., 8, 361-375, doi:10.3390/rs8050361, 2016.

Liu, Y., Cai, Z., Yang, D., Duan, M., and Lü, D.: Optimization of the instrument configuration for TanSat $\mathrm{CO}_{2}$ spectrometer, Chinese Sci. Bull., 58, 2787-2789, 2013.

Long, D. A. and Hodges, J. T.: On spectroscopic models of the $\mathrm{O}_{2} A$-band and their impact upon atmospheric retrievals, J. Geophys. Res. 117, D12309, doi:10.1029/2012JD017807, 2012.

Massart, S., Agustí-Panareda, A., Heymann, J., Buchwitz, M., Chevallier, F., Reuter, M., Hilker, M., Burrows, J. P., Deutscher, N. M., Feist, D. G., Hase, F., Sussmann, R., Desmet, F., Dubey, M. K., Griffith, D. W. T., Kivi, R., Petri, C., Schneider, M., and Velazco, V. A.: Ability of the 4-D-Var analysis of the GOSAT BESD XCO-2 retrievals to characterize atmospheric $\mathrm{CO}_{2}$ at large and synoptic scales, Atmos. Chem. Phys., 16, 1653-1671, doi:10.5194/acp-16-1653-2016, 2016.

O’Brien, D. M., Polonsky, I., O’Dell, C., Kuze, A., Kikuchi, N., Yoshida, Y., and Natraj, V.: Testing the polarization model for TANSO-FTS on GOSAT against clear-sky observations of sunglint over the ocean, IEEE Geosci. Remote S., 5199-5209, doi:10.1109/TGRS.2012.2232673, 2013.

O’Dell, C., Polonsky, I. N., Frankenberg, C., Crisp, D., Eldering, A., Gunson, M. R., Wunch, D., Wennberg, P. O., and Chevallier, F.: Analysis of four years of GOSAT data through the ACOS B3.4 retrieval algorithm, AGU Fall Meeting, San Francisco, USA, 913 December 2013, A13K-05, 2013.

Parker, R. J., Boesch, H., Wooster, M. J., Moore, D. P., Webb, A. J., Gaveau, D., and Murdiyarso, D.: Atmospheric $\mathrm{CH}_{4}$ and $\mathrm{CO}_{2}$ enhancements and biomass burning emission ratios derived from satellite observations of the 2015 Indonesian fire plumes, Atmos. Chem. Phys. Discuss., doi:10.5194/acp-2016-233, in review, 2016.

Sanghavi, S., Lebsock, M., and Stephens, G.: Sensitivity analysis of polarimetric $\mathrm{O}_{2}$ A-band spectra for potential cloud retrievals using OCO-2/GOSAT measurements, Atmos. Meas. Tech., 8, 3601-3616, doi:10.5194/amt-8-3601-2015, 2015.

Shiomi, K., Kawakami, S., Kuze, A., Suto, H., Hashiguchi, T., Kataoka, F., Higuchi, R., Bruegge, C., and Schwandner, F.: Onorbit lunar calibration compared with vicarious calibration for GOSAT, AGU Fall Meeting, San Francisco, USA, 9-13 December 2013, A21G-0159, 2013.

Suto, H., Frankenberg, C., Crisp, D., and Kuze, A.: Characterization and correction of non-linearity effect on oxygen spectra of TANSO-FTS onboard GOSAT, AGU Fall Meeting, San Francisco, USA, 5-9 December 2011, A33C-0210, 2011.

Suto, H., Yoshida, J., Desbiens, R., Kawashima, T., and Kuze, A.: Characterization and correction of spectral distortions induced by microvibrations onboard the GOSAT Fourier transform spectrometer, Appl. Opt., 52, 4969-4980, 2013a.

Suto, H., Kuze, A., Shiomi, K., and Nakajima, M.: Space-based carbon monitoring by GOSAT and GOSAT-2: Lessons learned from GOSAT in-orbit operation and towards better accuracy of $\mathrm{X}_{\mathrm{CO} 2}$ observation, AGU Fall Meeting, San Francisco, USA, 9-13 December 2013, A13K-07, 2013b.

Suto, H., Butz, A., and Kuze, A.: Correction of spectral distortion on Oxygen A-band due to non-linear phase delay onboard TANSOFTS/GOSAT, AGU Fall Meeting, San Francisco, USA, 15-19 December 2014, A41H-3153, 2014.

Thompson, D. R., Benner, D. C., Brown, L. R., Crisp, D., Devi, V. M., Jiang, Y., Natraj, V., Oyafuso, F., Sung, K., Wunch, D., Castano, R., and Miller, C. E.: Atmospheric validation of high accuracy $\mathrm{CO}_{2}$ absorption coefficients for the OCO-2 mission, J. Quant. Spectrosc. Ra., 113, 2265-2276, 2012.

Turner, A. J., Jacob, D. J., Wecht, K. J., Maasakkers, J. D., Lundgren, E., Andrews, A. E., Biraud, S. C., Boesch, H., Bowman, K. W., Deutscher, N. M., Dubey, M. K., Griffith, D. W. T., Hase, F., Kuze, A., Notholt, J., Ohyama, H., Parker, R., Payne, V. H., Sussmann, R., Sweeney, C., Velazco, V. A., Warneke, T., Wennberg, P. O., and Wunch, D.: Estimating global and North American methane emissions with high spatial resolution using GOSAT satellite data, Atmos. Chem. Phys., 15, 7049-7069, doi:10.5194/acp-15-7049-2015, 2015.

Toon, G. C., Blavier, J. F., Sen, B., Kleinboehl, A., Boesch, H., Sung, K., Nair, Frankenberg, C., and Aaron, S.: Improved solar reference spectrum, Pasadena, International Workshop on Greenhouse Gas Measurements from Space, Pasadena, USA, 16-18, June 2015, PS2, 2015.

Uprety, S. and Cao, C.: VIIRS bias analysis using Hyperion, HyspIRI Product Symposium, Greenbelt, USA, 3-5 June 2015, IV-A, 2015.

Veefkind, J., Aben, I., McMullan, K., Förster, H., de Vries, J., Otter, G., Claas, J., Eskes, H., de Haan, J., Kleipool, Q., van Weele, M., Hasekamp, O., Hoogeveen, R., Landgraf, J., Snel, R., Tol, P., 
Ingmann, P., Voors, R., Kruizinga, B., Vink, R., Visser, H., and Levelt, P.: TROPOMI on the ESA Sentinel-5 precursor: a GMES mission for global observations of the atmospheric composition for climate, air quality and ozone layer applications, the Sentinel missions - new opportunities for science, Remote Sens. Environ., 120, 70-83, doi:10.1016/j.rse.2011.09.027, 2012.

Wunch, D., Toon, G. C., Blavier, J.-F. L., Washenfelder, R. A., Notholt, J., Connor, B. J., Griffith, D. W. T., Sherlock, V., and Wennberg, P. O.: The Total Carbon Column Observing Network, Phil. Trans. R. Soc. A, 369, 2087-2112, 2011.
Yoshida, Y., Kikuchi, N., Morino, I., Uchino, O., Oshchepkov, S., Bril, A., Saeki, T., Schutgens, N., Toon, G. C., Wunch, D., Roehl, C. M., Wennberg, P. O., Griffith, D. W. T., Deutscher, N. M., Warneke, T., Notholt, J., Robinson, J., Sherlock, V., Connor, B., Rettinger, M., Sussmann, R., Ahonen, P., Heikkinen, P., Kyrö, E., Mendonca, J., Strong, K., Hase, F., Dohe, S., and Yokota, T.: Improvement of the retrieval algorithm for GOSAT SWIR $\mathrm{XCO}_{2}$ and $\mathrm{XCH}_{4}$ and their validation using TCCON data, Atmos. Meas. Tech., 6, 1533-1547, doi:10.5194/amt-6-1533-2013, 2013. 